\title{
Elements of Social Convoy Theory in Mobile Health for Palliative Care: Scoping Review
}

Jennifer D Portz ${ }^{1}$, PhD, MSW; Kira Elsbernd ${ }^{2}$, MPH; Evan Plys ${ }^{1}$, PhD; Kelsey Lynett Ford ${ }^{2}$, MPH; Xuhong Zhang ${ }^{2}$, $\mathrm{PhD}$; M Odette Gore ${ }^{3,4}$, MD, MSCS; Susan L Moore ${ }^{2}$, PhD, MSPH; Shuo Zhou ${ }^{2}$, PhD; Sheana Bull², PhD, MPH

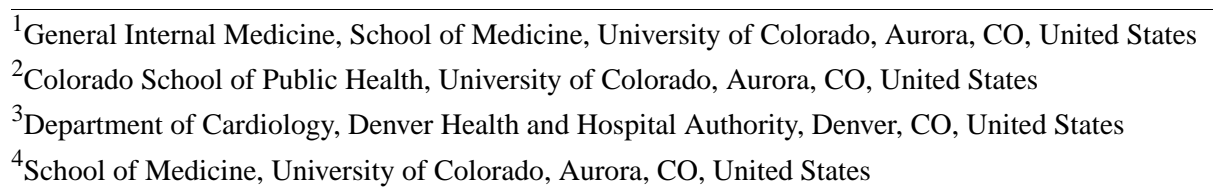

Corresponding Author:

Jennifer D Portz, PhD, MSW

General Internal Medicine, School of Medicine

University of Colorado

13055 E 17 th

F802

Aurora, CO, 80045

United States

Phone: 13037248856

Email: jennifer.portz@cuanschutz.edu

\section{Abstract}

Background: Mobile health (mHealth) provides a unique modality for improving access to and awareness of palliative care among patients, families, and caregivers from diverse backgrounds. Some mHealth palliative care apps exist, both commercially available and established by academic researchers. However, the elements of family support and family caregiving tools offered by these early apps is unknown.

Objective: The objective of this scoping review was to use social convoy theory to describe the inclusion and functionality of family, social relationships, and caregivers in palliative care mobile apps.

Methods: Using the Preferred Reporting Items for Systematic Reviews and Meta-Analyses extension for Scoping Review guidelines, a systematic search of palliative care mHealth included (1) research-based mobile apps identified from academic searches published between January 1, 2010, and March 31, 2019 and (2) commercially available apps for app stores in April 2019. Two reviewers independently assessed abstracts, app titles, and descriptions against the inclusion and exclusion criteria. Abstracted data covered app name, research team or developer, palliative care element, target audience, and features for family support and caregiving functionality as defined by social convoy theory.

Results: Overall, 10 articles describing 9 individual research-based apps and 22 commercially available apps were identified. Commercially available apps were most commonly designed for both patients and social convoys, whereas the majority of research apps were designed for patient use only.

Conclusions: Results suggest there is an emerging presence of apps for patients and social convoys receiving palliative care; however, there are many needs for developers and researchers to address in the future. Although palliative care mHealth is a growing field, additional research is needed for apps that embrace a team approach to information sharing, target family- and caregiver-specific issues, promote access to palliative care, and are comprehensive of palliative needs.

(JMIR Mhealth Uhealth 2020;8(1):e16060) doi: $\underline{10.2196 / 16060}$

\section{KEYWORDS}

mHealth; palliative care; caregivers; mobile apps 


\section{Introduction}

\section{Background}

Nearly 1.7 million people will die in the United States each year from a serious chronic illness, including heart disease, cancer, and respiratory disease [1]. These patients experience significant physical and psychological symptom burden and progressive dependence on their family and caregivers [2]. For the months or years leading to death, palliative care provides an interdisciplinary and patient-family centered approach to address the physical, psychological, emotional, and spiritual suffering for patients and families [3]. The primary goal of palliative care is to improve quality of life.

Palliative care is provided by an interdisciplinary team often made up of physicians, nurses, social workers, and chaplains. Specialty services including physical therapy, occupational therapy, and music or art therapy may also be offered. Palliative care strategies target symptom management, medication management, family support and training, advance care planning and goals of care facilitation, caregiver respite, and interventions for emotional and spiritual needs of patients and family [4]. Hospice is a specific type of palliative care provided in the terminal phase of end-of-life care. Hospice provides 24-hours a day palliative care services focused on symptom management, provision of needed medical equipment, psychospiritual and emotional aspects of dying, respite care, family coaching, bereavement, and grief services. In the United States, hospice is specifically associated with the Hospice Medicare Benefit and is provided only to terminally ill patients with a life expectancy of 6 months or less who no longer seek potentially curative treatment such as chemotherapy and dialysis.

Palliative care improves patient and family reported outcomes, including quality of life and satisfaction, reductions in emergency visits and hospitalizations at end-of-life, and increased referral and length of stay with hospice services [5]. However, estimates suggest that only $3.4 \%$ of hospital admissions are referred to palliative care. Nearly 1 million patients admitted who could benefit from palliative care do not receive this specialized service [6]. Access barriers to palliative care are commonly attributed to palliative care resource availability, lack of awareness, and provider and patient and family reluctance [7].

Mobile health (mHealth), the use of mobile devices to improve health services and health outcomes, provides modern opportunities for patients and their family to engage in palliative care but is relatively underexplored. mHealth may provide access to palliative care support for patients and families that may not otherwise receive specialty palliative care or hospice services. There are mHealth palliative care apps available commercially, and health-related researchers are currently initiating app design efforts [8,9]. However, the elements of family support and family caregiving tools offered by these early apps is unknown.

On the basis of a national survey of caregivers, an estimated $40 \%$ to $65 \%$ of family caregivers are interested in using mHealth to support and monitor the health of their loved ones [10,11]; however, mHealth systems are typically designed for individual users, rather than integrating the patient's family, friends, and social support to maximize benefit. This contradicts the behavioral science findings indicating social support is a critical construct in improving health behaviors and health outcomes. Specifically, Social Convoy Theory [12-14] is well established in the social science literature and provides a framework for understanding the complex relationships of individuals within a group of people that give and receive social support over the life cycle. The convoy can include informal supports such as family members, friends, and neighbors and formal supports such as professional caregivers. Previous research substantiates a link between social convoys and convoy relationships with improved health outcomes, reduced mortality in older populations, and quality of life among patients with serious illness [15-17]. The structure, function, and quality of one's social convoy is associated with quality of life, the primary health outcome for palliative care. Therefore, when designing mHealth specially for palliative care, it is important to incorporate a social convoy perspective considering that the family is a key component of care. As people with serious illness increasingly rely on the support of others to help manage their health, there is a critical need to foster approaches for effective integration of the convoy in palliative care-specific mHealth.

\section{Objective}

Although palliative care improves health outcomes and quality of life, there are barriers to accessing specialty services. Growing acceptability of mHealth offers promise in leveraging tools with family and the caregiving team to expand access. The objective of this scoping review was to describe the integration of social convoy theory in current palliative care-specific mHealth. Findings from this work will be used to inform strategies for designing mHealth interventions that are not only addressed to individual patients but also integrate their social convoy of families, friends, and caregivers.

\section{Methods}

\section{Scoping Review}

As little is known about palliative care mHealth, a scoping review approach was used to comprehensively review palliative care-specific mobile apps to determine the extent and nature of social convoy features available. The Preferred Reporting Items for Systematic Reviews and Meta-Analyses extension for Scoping Review (PRISMA-ScR) checklist guided the work, informing the search, selection, and evaluation of mobile apps [18]. This review is unique as it applies the PRISMA-ScR method to review both commercially available apps (offered from app stores) and research-based apps (described in the health-related scientific literature) to systematically review all current palliative care-specific apps.

\section{App Search and Screening}

To identify research-based apps, the search utilized 3 academic databases including PubMed, PsycINFO, and Web of Science for peer-reviewed palliative care mHealth studies. The search included empirical studies published between January 1, 2010, and March 31, 2019. The search string was restricted to search 
terms included in the title and abstract and included: palliative care OR hospice OR end-of-life OR terminal illness OR advance directives OR living will OR symptom OR advanced care planning OR spiritual care OR grief OR bereavement AND mobile OR smartphone OR app OR mHealth. This search string ensured that only mHealth interventions for palliative care specially were identified. Systematic review articles were not included in the final scoping review, rather the specific apps listed in the reviews' results were assessed for inclusion. In addition to research-based apps, an electronic search in April 2019 browsed official app stores for iPhone (Apple Inc [iOS,
The App Store]), Google Play (Google, LLC [Android, ChromeOS, Google Play Store]), and Amazon Appstore (Amazon Inc [Android, FireOS, Blackberry, Amazon App Store]) to identify free, commercially available palliative care apps. Identical palliative care terms were used as listed above, which have previously been used to identify mHealth interventions directed toward palliative care [8]. Duplicate articles and apps were removed before screening eligibility. A summary of search and screening process is described in Figure 1.

Figure 1. Flowchart for selection of research-based and commercially available apps.

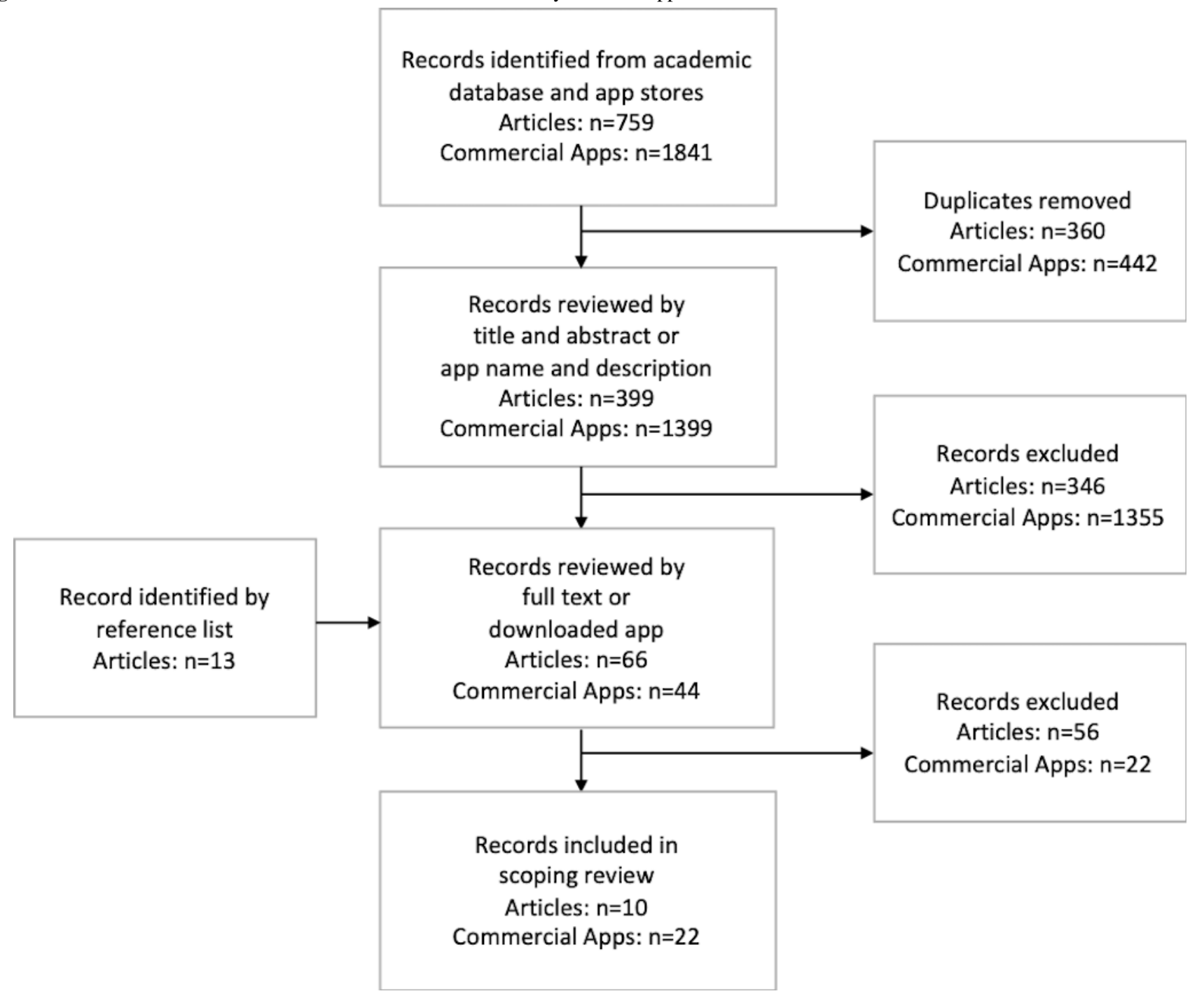

Mobile apps meeting the following inclusion criteria were included in the review: (1) focused on at least one element of palliative care (quality of life assessment, symptom management, family support including bereavement or grief, spiritual care, psychosocial support, decision support, and patient/family education), (2) targeted adults with serious life-limiting illness and/or their family and caregivers, and (3) offered via a mobile app, that is, articles using websites that can be accessed via a mobile device were not included in this review. The primary reasons apps were excluded from the review are as follows: not available for free, not available in English, not available in the United States, pediatric focus, provider targeted, hospice eligibility and referral only, funeral planning only, and theoretical prototypes. Articles that did not provide detailed description of the mobile app were excluded.

To determine if apps met inclusion criteria, 2 coders (JDP and $\mathrm{KE}$ ) independently reviewed the academic articles by title and abstract and screened commercial apps by app name and description provided by the app store. The full text of articles was then downloaded and further reviewed for eligibility. Commercially available apps were downloaded, and a user account was established. The coders met regularly to review articles and commercial apps to discuss questions and possible disputes. Both coders agreed on the final apps included in the 
review. The search and screening process resulted in 10 articles [19-28] describing 9 individual research-based apps and 22 commercially available apps. Furthermore, none of the included research-based apps were available commercially.

\section{Data Extraction}

Once included, information about the apps were abstracted into a Microsoft Excel spreadsheet. Abstracted data covered app name, research team or developer (individual or organization), palliative care element, target audience (patient, convoy, or both), and features for family support and caregiving functionality as defined by Social Convoy Theory. Review of research-based apps was based on the description of app features provided in the article, whereas all tabs and features of commercially available apps were reviewed for the elements listed above. Apps were considered patient-focused if features were designed primarily for patients, such as education or symptom tracking without the ability to share information captured in the app with caregivers; convoy-focused if features were designed primarily for caregivers, such as bereavement tools; and both patient and convoy-focused if app features were designed to share information and facilitate a patient-convoy relationship. Specifically, information was abstracted related to (1) convoy composition-app targets particular convoy relationships such as informal caregivers, formal caregivers, family, neighbors, friend, and/or other convoy members; (2) convoy size - the number of convoy members that can use the app; (3) personal convoy characteristics-app considerations of factors such as age, race, ethnicity, and/or gender of the patient and convoy; (4) contextual convoy characteristics-app considerations of factors such as marriage, social isolation, and/or socioeconomic status of the patient and convoy; and (5) convoy support-app facilitation between patient and convoy.

\section{Results}

\section{Summary of Apps}

A summary of social convoy elements in palliative care mHealth is provided in Table 1. Overall, 22 commercially available mobile apps (Table 2) and 10 articles describing 9 apps (Table 3 ) were selected for full review. A total of 11 of 22 apps were available through the Apple app store only, 3 through the Google store only, 7 were available through both Apple and Google stores, 1 through Google and Amazon app stores, and 1 through all 3 app stores. Apps identified in the literature were in various stages of development, which included articles describing at least a minimum viable product. A total of 6 of the 9 apps identified were prototypes undergoing acceptability and/or usability pilot testing, a further 2 apps were under evaluation in randomized controlled trials with no results yet available, and 1 article described results from a randomized controlled trial using an app-based intervention.

Table 1. Commercially available and research app elements $(\mathrm{N}=31)$.

\begin{tabular}{|c|c|c|}
\hline Element & Commercial (n=22), n (\%) & Research $(n=9), n(\%)$ \\
\hline \multicolumn{3}{|l|}{ Primary palliative care component } \\
\hline Quality of life & $1(5)$ & $0(0)$ \\
\hline Psychosocial support & $3(14)$ & $0(0)$ \\
\hline Decision support & $5(23)$ & $1(11)$ \\
\hline Symptom management & $15(48)$ & $8(89)$ \\
\hline Bereavement or grief & $5(23)$ & $0(0)$ \\
\hline Patient/family education & $1(4.5)$ & $0(0)$ \\
\hline \multicolumn{3}{|l|}{ Target user } \\
\hline Patient & $8(36)$ & $8(89)$ \\
\hline Convoy & $5(23)$ & $1(11)$ \\
\hline Both patient and convoy & $9(41)$ & $0(0)$ \\
\hline \multicolumn{3}{|l|}{ Convoy composition and size } \\
\hline Convoy can be independent app users & $4(18)$ & $1(11)$ \\
\hline Convoy can be independent users but are not connected & $3(14)$ & $0(0)$ \\
\hline Patient shares app-generated content with convoy & $10(45)$ & $0(0)$ \\
\hline Targets patient only & $5(23)$ & $8(89)$ \\
\hline Considers age, race, ethnicity, and gender & $6(27)$ & $1(11)$ \\
\hline Considers marriage, social isolation, and socioeconomic status & $2(9)$ & $0(0)$ \\
\hline
\end{tabular}


Table 2. Summary of commercial apps.

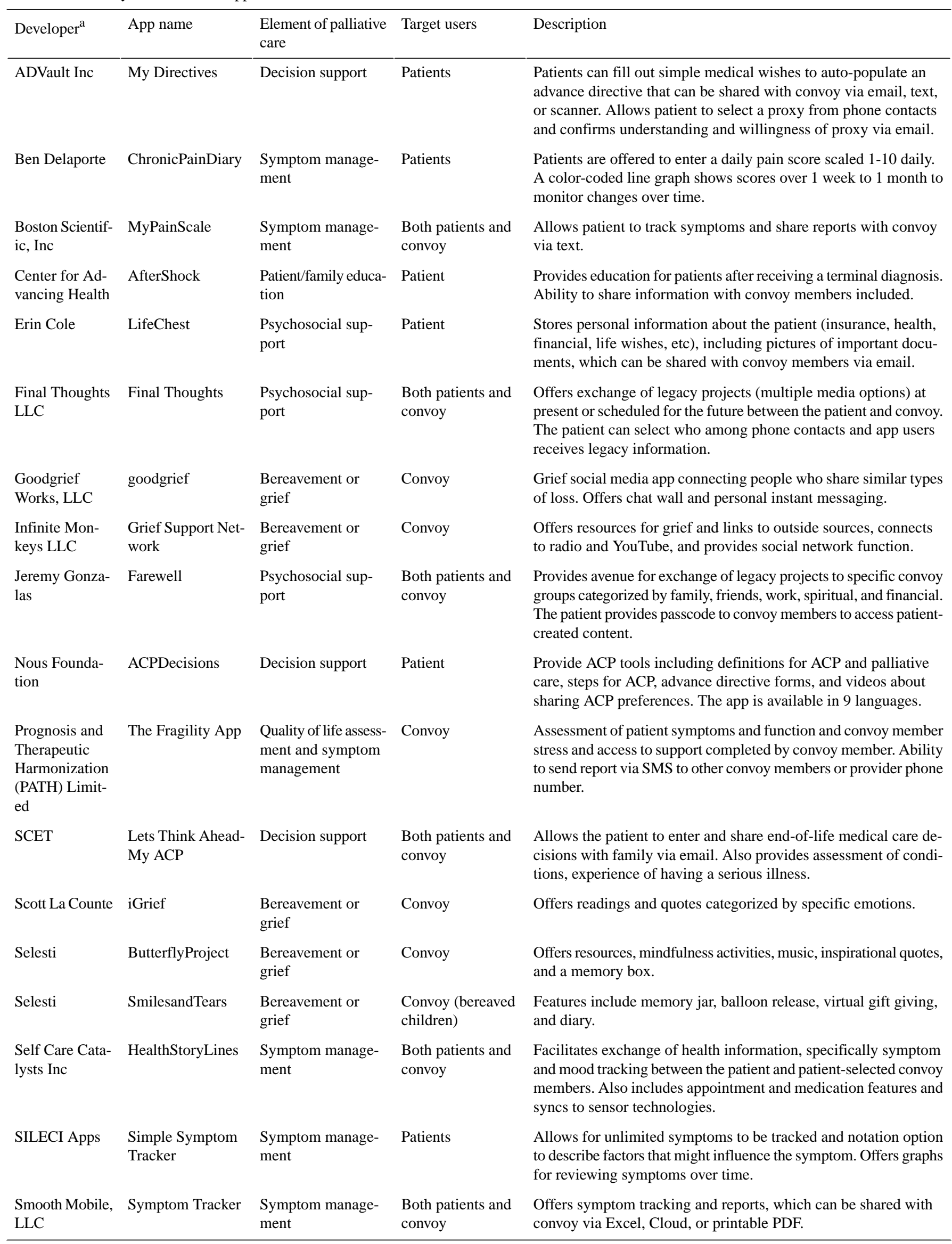




\begin{tabular}{lllll}
\hline Developer $^{\mathrm{a}}$ & App name & $\begin{array}{l}\text { Element of palliative } \\
\text { care }\end{array}$ & Target users & Description \\
\hline VJ Periyakoil & $\begin{array}{l}\text { AdvanceDirectives } \\
\text { Stanford Universi- } \\
\text { ty }\end{array}$ & $\begin{array}{l}\text { Decision support } \\
\text { mPalliative Care }\end{array}$ & $\begin{array}{l}\text { Patients } \\
\text { Symptom manage- }\end{array}$ & $\begin{array}{l}\text { Stores patient medical and emergency information, organ donation, } \\
\text { and end-of-life medical care decisions, which can be shared with } \\
\text { convoy via email. Includes ability to add pictures or video. }\end{array}$ \\
$\begin{array}{l}\text { Universal } \\
\begin{array}{l}\text { Projects and } \\
\text { Tools, SL }\end{array}\end{array}$ & App & convoy & $\begin{array}{l}\text { Patients can track symptoms and share reports with convoy via } \\
\text { text. }\end{array}$ \\
$\begin{array}{l}\text { University of } \\
\text { Zurich }\end{array}$ & Catch My Pain & $\begin{array}{l}\text { Symptom manage- } \\
\text { ment }\end{array}$ & $\begin{array}{l}\text { Both patients and } \\
\text { convoy }\end{array}$ & $\begin{array}{l}\text { Patients can track symptoms and share reports with convoy via } \\
\text { text. }\end{array}$ \\
\hline $\begin{array}{l}\text { Billiam Palin } \\
\text { Decision support }\end{array}$ & PaperHealth & $\begin{array}{l}\text { Allows patients to enter and share designated health proxy and } \\
\text { end-of-life care preferences with convoy via email or text. }\end{array}$ \\
\hline
\end{tabular}

${ }^{a}$ Commercial apps were not directly connected to health care providers or clinical electronic medical record. All apps provided at least one export function for data that could be shared with providers via the patient or caregiver.

Table 3. Summary of research apps.

\begin{tabular}{lllll}
\hline Study & App name & $\begin{array}{l}\text { Element of palliative } \\
\text { care }\end{array}$ & Target user & Description \\
\hline $\begin{array}{l}\text { Agboola et al (2014) } \\
\text { [19]; Fishbein et al } \\
\text { (2017) [20] }\end{array}$ & CORA & $\begin{array}{l}\text { Symptom manage- } \\
\text { ment }\end{array}$ & $\begin{array}{l}\text { Patients on oral anti- } \\
\text { cancer medication }\end{array}$ & $\begin{array}{l}\text { Provides daily educational and/or support push notifica- } \\
\text { tions, offers symptom reporting and strategies for symp- } \\
\text { tom management, weekly symptom and activity reports, } \\
\text { and is customizable to patient needs, abilities, and medi- } \\
\text { cations. }\end{array}$ \\
$\begin{array}{l}\text { Agboola et al (2014) } \\
\text { [21] }\end{array}$ & ePAL & $\begin{array}{l}\text { Symptom manage- } \\
\text { ment }\end{array}$ & Patients with cancer & $\begin{array}{l}\text { Offers on-demand pain assessments, daily educational } \\
\text { and/or support push notifications, multimedia resource } \\
\text { library including psychosocial support material, prescrip- } \\
\text { tion refills, and ability to personalize based on self-report- } \\
\text { ed barriers to pain management. Also facilitates patient- } \\
\text { provider communication through direct call button and } \\
\text { provider access to patient-entered information. }\end{array}$
\end{tabular}

Alnosayan et al (2017) MyHeart

[22]

Symptom management

Patients with heart

failure

Athilingam et al (2016) HeartMapp

[23]

PCplanner

Decision support

Symptom manage- $\quad$ Patients with heart ment

failure

Convoy

Foster (2018) [25] $\quad$ HF App

Hardinge et al (2015) Not applicable [26]

Moradian et al (2018) ASyMS

[27]

Triantafyllidis et al (2015) [28]
SUPPORT-HF

Symptom management
Symptom management

Symptom management

Symptom management

Patients with heart failure

ure

Patients aged $>50$ years with chronic disease
Patients aged $>50 \quad$ Offers daily symptom and vitals tracking and heart failure years with heart fail- educational resources. obstructive pulmonary

Patients with cancer

Offers symptom and well-being diary, including optional recording of medication use, collected through app and sensor technologies. Personalized plans for self-management and educational material also included.

Offers functionalities for monitoring and managing chemotherapy-related toxicity with personalized risk prediction modeling and decision support. High-severity symptom reports alert clinicians.

Offers symptom tracking and reports, educational material, and ability to communicate with clinicians through app. 


\section{Elements of Palliative Care and Target User}

The majority of apps (15 commercial and 8 research apps) primarily targeted symptom management, followed by decision support ( 5 commercial and 1 research app) and bereavement or grief ( 5 commercial apps). Commercially available apps were most commonly designed for patients ( 8 apps) or both patients and convoy ( 9 apps), whereas the majority of research apps ( 8 apps) were designed for patient use only. The research apps primarily targeted a specific condition (8 apps), cancer, heart failure, or Chronic Obstructive Pulmonary Disease, whereas commercial apps focused on a more general population providing functions for multiple symptoms, various psycho-social support, and health decision making resources.

\section{Convoy Composition and Size}

Among commercially available apps, features allowing the patient to share app-generated materials, for example, advanced care directives or legacy projects, via email or SMS text message, were the most common (10 apps) in terms of patient-convoy relationship facilitated by the app. Several apps allowed convoy members to be independent users, either connected to the patient and other convoy members (4 commercial apps and 1 research app) or not (3 commercial apps). An additional 5 commercial apps and the majority of research apps (8 apps) did not have a convoy component and targeted the patient only.

\section{Consideration of Personal and Contextual Characteristics}

Several apps (5 commercial and 1 research) gave consideration to personal characteristics including age, gender, race, and ethnicity of the patient and/or convoy members. Few apps (2 commercial) considered contextual factors such as marriage, social isolation, or socioeconomic status of patient or convoy members. Furthermore, only 1 app included both personal and contextual characteristics.

\section{Discussion}

\section{Principal Findings}

mHealth may offer a simple, cost-effective method for keeping individuals connected and involved in care across the course of serious illness. This scoping review described the support for access and use by social convoy members in mHealth apps for palliative care. Overall, this review identified strengths, weaknesses, and areas for future work in mHealth for palliative care.

Results identified 14/22 (64\%) commercial apps and 1/9 (11\%) research app that included convoy members; however, only 5 in total, all of which were commercial apps, targeted convoy members as primary users. The vast difference in convoy-inclusion results yielded from research-based versus commercial apps suggests that the mHealth market considers caregivers consumers of their product, whereas researchers are focusing on patient-directed care. Although caregivers may be increasingly seen as potential users among developers, a recent review indicates that there are few commercial apps available specifically for caregiving [29] and limited usability evidence for caregiver apps [30]. Even though the inclusion of convoys in multiple apps was promising, convoy members were often passive recipients of information, and few apps targeted convoy-specific issues.

Many of the apps included in this review allowed patients to share information with convoy members regarding symptom management, decision making, and preferences. A strength of this feature is that sharing information may help convoy members understand symptom presentation, burden, and management. This is important in palliative care as families often struggle to identify the presence or severity of key symptoms (eg, pain or psychological distress) [31]. In addition, quick and convenient access to documentation of proxies and patient preferences may help establish consistency in decision making, promote confidence in time-limited decisions, and decrease decisional conflict. However, more research is needed to test the effect of sharing health information with social convoys on positive palliative care outcomes, including quality of life, symptom management, and goal concordant care.

Commercial apps offered tools and resources for a general audience, whereas research apps targeted specific illnesses. Often people with palliative care needs have more than one condition, and disease specific apps may be too limited. However, some mobile interventions may require specificity to address disease specific symptoms and improve health decision making. For example, illness trajectories differ by condition. Therefore, preparing advance directives or goals of care in the setting of heart failure can be different than treatment options for cancer. This specificity may not be available in more generalized palliative care apps.

A limitation of the symptom management and decision-making apps included in this review is that, typically, convoy members were passive recipients of information (ie, a 1-way flow of information from patient to convoy). Although patients' ability to manage the dissemination of information may promote choice and control, there are also limitations to this structure. For example, cognitive impairment, pain, and/or fatigue may hinder motivation or ability to share information with convoy members, which may result in misinformation or conflict. In addition, ideally, palliative care follows a team-based approach with information continually flowing to and from patients, providers, and convoys rather than a single party disseminating information to others. Additional work needs to be done to investigate mHealth methods that support a patient-centered model of care and empower active involvement from convoy members.

The individual, social, or care-related outcomes of a hub (patient) and spoke (convoy members) model of flow of information, consistent with many of the apps included in this review, are unknown. As mentioned, this model may increase choice and control but might also relate with perceived sense of burden for patients. For example, sharing daily pain levels may increase the patient's perceived burden on others and/or convoy members' sense of helplessness. Future research is needed to explore relationships between mHealth use, convoy contact, perceived burden, and other salient outcomes (eg, relationship quality, satisfaction with care, or quality of life). 
Coping with bereavement and grief was the most common palliative care component of apps targeting convoy members as primary users. Although grief occurs across the course of serious illness [32], the majority of apps were tailored to coping with bereavement after the death of the patient. These apps included common coping strategies such as connecting with social support, resource sharing and education, affirmations, and tracking behaviors or rituals. Accepted models of bereavement and grief suggest that individuals cope with stressors related to loss (ie, negative emotions) and restoration (ie, negotiating new roles) [33]. However, most of the apps included in this review focused on coping with loss-related stressors only, omitting any focus on restoration. Therefore, current mHealth apps for palliative care may not offer comprehensive coping tools for bereavement and grief and may be most useful early in the bereavement process (ie, soon after the death of a loved one). Future work needs to investigate how convoy members use mHealth apps for bereavement and grief and the impact of such app use on the coping process.

Few mHealth apps included in this review targeted convoy-specific issues other than bereavement and grief. Additional convoy-specific issues in palliative care not addressed by apps in this review include: care roles (eg, defining and providing education on roles among convoy members), skills and coping (eg, time management, stress reduction, or anticipatory grief), and communication (eg, planning family meetings, conflict resolution, or assertiveness training). The aforementioned topics, however, are not a comprehensive list of convoy-specific issues in palliative care, and engaging stakeholders may help developers and researchers design improved apps to meet the specific needs of this population.

A minority of apps included in this review considered convoy characteristics in development. Personal factors such as age, socioeconomic status, marriage, and social support likely influence preferences, needs, and usability for mHealth apps and, thus, should be considered in future works. Distance and relationship quality are also important convoy characteristics that were not considered in any app included in this review. $\mathrm{mHealth}$ may be particularly useful for facilitating involvement and meeting the needs of long-distance convoy members; however, this population is rarely given unique consideration in the development of interventions. Attention to relationship quality and conflict among patients, convoy members, and providers may be another important area to consider in future mHealth interventions. For example, apps may choose to offer settings and features to control the flow of information based on the quality of relationship, or offer strategies to address interpersonal conflict. Taken together, developers and researchers should appreciate the heterogeneity of convoy members and populations with unique needs, as this may impact needs, usage, and outcomes.

This review identified multiple areas for future app development and research in mHealth for palliative care. First, there is a need to consider team-based apps that promote active roles and flow of information among patients, convoy members, and providers. Second, few apps considered convoy-specific needs or characteristics, which may limit the reach and benefit of mHealth in palliative care. Next, many apps targeted individuals already connected to palliative services but did not address the potential of mHealth to help promote access to palliative care. Additional apps are needed to provide education and resources for connecting individuals with serious illness and their convoys with palliative care services. Finally, the apps included in this review isolated specific components of palliative care, possibly increasing user burden and/or decreasing usage by requiring various apps to meet palliative care needs. Additional work is needed to develop holistic mHealth apps consistent with the comprehensive palliative model of care (ie, biopsychosocial-spiritual).

Only 1 research app identified in this review included convoy members in any way, and that app did not target convoy members as primary users. The omission of convoys in research limits empirical knowledge on the reach and impact of mHealth in palliative care and raises questions regarding possible research challenges with this population. Previous scholars suggest there are unique challenges related to research with patients with serious illness and their care networks [34], but it is possible that app-based data collection may actually alleviate some of these issues (eg, fewer recruitment challenges). Therefore, it is unknown whether the scientific mission of mHealth apps in palliative care has narrowly focused on patients or if there are methodological limitations that create barriers for including this population in research. Additional work is needed to address best practices for mHealth research in palliative care, particularly related to the inclusion of social convoys.

\section{Strengths and Limitations}

To the knowledge of the authors, this scoping review is the first to address the inclusion and function of social convoys in commercial and research mHealth apps for palliative care. As a result, our findings and interpretations may be instrumental for guiding future work in mHealth for palliative care, an emerging area of industry and science. However, there are some limitations to highlight. First, this review only included free commercially available apps from 3 major app stores, which may have biased findings. Furthermore, as apps identified in the research were unavailable commercially, review of research-based apps relied solely on the description of the app in the publication. Second, the scope of review did not consider mHealth solutions other than mobile apps. There are many palliative care digital health initiatives, including telemedicine, websites, and text message programs, currently underway to expand access to palliative care. However, mobile apps have the ability to offer palliative care tools and functions with and without access to the internet. Third, this review considered both commercial apps and apps developed in research settings and reported on features and functions available in the resulting products but did not assess the presence or strength of the evidence base with regard to the impact of any of the apps on their intended outcomes. In the absence of an evidence base, it is difficult to compare apps, and are therefore limited to describing the functions of palliative care apps rather than assessing quality.

\section{Conclusions}

This scoping review highlighted important information on the inclusion and functionality of social convoy members in 
mHealth apps for palliative care. Results suggest there is an emerging presence of apps for patients and convoy members receiving palliative care; however, there are many needs for developers and researchers to address in the future. Specifically, additional work is needed for apps that embrace a team approach to information sharing, target convoy-specific issues, promote access to palliative care, and are comprehensive of palliative needs. Furthermore, the inclusion of convoys in mHealth research is severely lacking and requires attention in the literature. Limitations and recommendations presented in this review may help guide future development of mHealth apps and scientific studies designed to support the needs of patients and convoy members in palliative care.

\section{Acknowledgments}

This research is funded by a career development award (K76AG059934) and training support (T32AG044296) from the National Institute on Aging.

\section{Conflicts of Interest}

None declared.

\section{References}

1. Centers for Disease Control and Prevention. 2015. Chronic Diseases in America URL: https://www.cdc.gov/chronicdisease/ resources/infographic/chronic-diseases.htm [accessed 2019-11-07]

2. Morrison RS. Research priorities in geriatric palliative care: an introduction to a new series. J Palliat Med 2013 Jul;16(7):726-729 [FREE Full text] [doi: 10.1089/jpm.2013.9499] [Medline: 23721426]

3. Quill TE, Miller FG. Palliative Care and Ethics. Oxford, United Kingdom: Oxford University Press; 2016.

4. National Hospice and Palliative Care Organization. Palliative Care: An Explanation of Palliative Care URL: https://www. nhpco.org/palliative-care-overview/explanation-of-palliative-care/ [accessed 2019-11-07]

5. Kavalieratos D, Corbelli J, Zhang D, Dionne-Odom JN, Ernecoff NC, Hanmer J, et al. Association between palliative care and patient and caregiver outcomes: a systematic review and meta-analysis. J Am Med Assoc 2016 Nov 22;316(20):2104-2114 [FREE Full text] [doi: 10.1001/jama.2016.16840] [Medline: 27893131]

6. Morrison RS, Augustin R, Souvanna P, Meier DE. America's care of serious illness: a state-by-state report card on access to palliative care in our nation's hospitals. J Palliat Med 2011 Oct;14(10):1094-1096 [FREE Full text] [doi: 10.1089/jpm.2011.9634] [Medline: 21923412]

7. Hawley P. Barriers to access to palliative care. Palliat Care 2017;10:1178224216688887 [FREE Full text] [doi: 10.1177/1178224216688887] [Medline: 28469439]

8. Meghani SH, MacKenzie MA, Morgan B, Kang Y, Wasim A, Sayani S. Clinician-targeted mobile apps in palliative care: a systematic review. J Palliat Med 2017 Oct;20(10):1139-1147. [doi: 10.1089/jpm.2017.0070] [Medline: 28557549]

9. Greenle MM, Morgan B, Sayani S, Meghani SH. Identifying mobile apps targeting palliative care patients and family members. J Palliat Med 2018 Oct;21(10):1380-1385. [doi: 10.1089/jpm.2018.0157] [Medline: 30312126]

10. National Alliance for Caregiving. 2011. e-Connected Family Caregiver: Bringing Caregiving into the 21st Century URL: http://www.caregiving.org/data/FINAL eConnected Family Caregiver Study Jan\%202011.pdf [accessed 2019-11-11]

11. Fox S, Duggan M, Purcell K. Pew Research Center. 2013. Family Caregivers are Wired for Health URL: http://www. pewinternet.org/2013/06/20/family-caregivers-are-wired-for-health/ [accessed 2017-08-15]

12. Antonucci TC, Ajrouch KJ, Birditt KS. The convoy model: explaining social relations from a multidisciplinary perspective. Gerontologist 2014 Feb;54(1):82-92 [FREE Full text] [doi: 10.1093/geront/gnt118] [Medline: 24142914]

13. Antonucci TC, Fiori KL, Birditt K, Jackey LM. Convoys of social relations: integrating life-spanlife-course perspectives. In: Lerner RM, Lamb ME, Freund AM, editors. The Handbook of Life-Span Development. Hoboken, NJ, USA: John Wiley \& Sons, Inc; 2010.

14. Kahn RS, Antonucci TC, Baltes P, Brim O. Convoys over the life course: attachment, roles,social support. In: Featherman D, Lerner R, Perlmutter M, editors. Life-span Development And Behavior. New York: Academic Press; 1980:254-283.

15. Becofsky KM, Shook RP, Sui X, Wilcox S, Lavie CJ, Blair SN. Influence of the source of social support and size of social network on all-cause mortality. Mayo Clin Proc 2015 Jul;90(7):895-902 [FREE Full text] [doi: 10.1016/j.mayocp.2015.04.007] [Medline: 26055526]

16. Tomaka J, Thompson S, Palacios R. The relation of social isolation, loneliness, and social support to disease outcomes among the elderly. J Aging Health 2006 Jun;18(3):359-384. [doi: 10.1177/0898264305280993] [Medline: 16648391]

17. Seeman TE. Health promoting effects of friends and family on health outcomes in older adults. Am J Health Promot 2000;14(6):362-370. [doi: 10.4278/0890-1171-14.6.362] [Medline: 11067571]

18. Tricco AC, Lillie E, Zarin W, O'Brien KK, Colquhoun H, Levac D, et al. PRISMA extension for Scoping Reviews (PRISMA-ScR): checklist and explanation. Ann Intern Med 2018 Oct 2;169(7):467-473. [doi: 10.7326/M18-0850] [Medline: $\underline{30178033}$ ] 
19. Agboola S, Flanagan C, Searl M, Elfiky A, Kvedar J, Jethwani K. Improving outcomes in cancer patients on oral anti-cancer medications using a novel mobile phone-based intervention: study design of a randomized controlled trial. JMIR Res Protoc 2014 Dec 23;3(4):e79 [FREE Full text] [doi: 10.2196/resprot.4041] [Medline: 25537463]

20. Fishbein JN, Nisotel LE, MacDonald JJ, Pensak NA, Jacobs JM, Flanagan C, et al. Mobile application to promote adherence to oral chemotherapy and symptom management: a protocol for design and development. JMIR Res Protoc 2017 Apr 20;6(4):e62 [FREE Full text] [doi: 10.2196/resprot.6198] [Medline: 28428158]

21. Agboola S, Kamdar M, Flanagan C, Searl M, Traeger L, Kvedar J, et al. Pain management in cancer patients using a mobile app: study design of a randomized controlled trial. JMIR Res Protoc 2014 Dec 12;3(4):e76 [FREE Full text] [doi: 10.2196/resprot.3957] [Medline: 25500281]

22. Alnosayan N, Chatterjee S, Alluhaidan A, Lee E, Feenstra LH. Design and usability of a heart failure mHealth system: a pilot study. JMIR Hum Factors 2017 Mar 24;4(1):e9 [FREE Full text] [doi: 10.2196/humanfactors.6481] [Medline: 28341615]

23. Athilingam P, Labrador MA, Remo EF, Mack L, San Juan AB, Elliott AF. Features and usability assessment of a patient-centered mobile application (HeartMapp) for self-management of heart failure. Appl Nurs Res 2016 Nov;32:156-163. [doi: 10.1016/j.apnr.2016.07.001] [Medline: 27969021]

24. Cox CE, Jones DM, Reagan W, Key MD, Chow V, McFarlin J, et al. Palliative care planner: a pilot study to evaluate acceptability and usability of an electronic health records system-integrated, needs-targeted app platform. Ann Am Thorac Soc 2018 Jan;15(1):59-68 [FREE Full text] [doi: 10.1513/AnnalsATS.201706-500OC] [Medline: 29121480]

25. Foster M. A mobile application for patients with heart failure: theory- and evidence-based design and testing. Comput Inform Nurs 2018 Nov;36(11):540-549. [doi: 10.1097/CIN.0000000000000465] [Medline: 30045131]

26. Hardinge M, Rutter H, Velardo C, Shah SA, Williams V, Tarassenko L, et al. Using a mobile health application to support self-management in chronic obstructive pulmonary disease: a six-month cohort study. BMC Med Inform Decis Mak 2015 Jun 18;15:46 [FREE Full text] [doi: 10.1186/s12911-015-0171-5] [Medline: 26084626]

27. Moradian S, Krzyzanowska MK, Maguire R, Morita PP, Kukreti V, Avery J, et al. Usability evaluation of a mobile phone-based system for remote monitoring and management of chemotherapy-related side effects in cancer patients: mixed-methods study. JMIR Cancer 2018 Dec 21;4(2):e10932 [FREE Full text] [doi: 10.2196/10932] [Medline: 30578238]

28. Triantafyllidis A, Velardo C, Chantler T, Shah SA, Paton C, Khorshidi R, SUPPORT-HF Investigators. A personalised mobile-based home monitoring system for heart failure: The SUPPORT-HF Study. Int J Med Inform 2015 Oct;84(10):743-753. [doi: 10.1016/j.ijmedinf.2015.05.003] [Medline: 26037921]

29. Grossman MR, Zak DK, Zelinski EM. Mobile apps for caregivers of older adults: quantitative content analysis. JMIR Mhealth Uhealth 2018 Jul 30;6(7):e162 [FREE Full text] [doi: 10.2196/mhealth.9345] [Medline: $\underline{30061093}$ ]

30. Quinn CC, Staub S, Barr E, Gruber-Baldini A. Mobile support for older adults and their caregivers: Dyad usability study. JMIR Aging 2019 May 23;2(1):e12276 [FREE Full text] [doi: 10.2196/12276] [Medline: 31518271]

31. McPherson CJ, Addington-Hall JM. Evaluating palliative care: bereaved family members' evaluations of patients' pain, anxiety and depression. J Pain Symptom Manage 2004 Aug;28(2):104-114. [doi: 10.1016/j.jpainsymman.2003.11.010] [Medline: 15276191]

32. Nielsen MK, Neergaard MA, Jensen AB, Bro F, Guldin M. Do we need to change our understanding of anticipatory grief in caregivers? A systematic review of caregiver studies during end-of-life caregiving and bereavement. Clin Psychol Rev 2016 Mar;44:75-93. [doi: 10.1016/j.cpr.2016.01.002] [Medline: 26796738]

33. Stroebe M, Schut H. The dual process model of coping with bereavement: rationale and description. Death Stud 1999;23(3):197-224. [doi: 10.1080/074811899201046] [Medline: 10848151]

34. Steinhauser KE, Clipp EC, Hays JC, Olsen M, Arnold R, Christakis NA, et al. Identifying, recruiting, and retaining seriously-ill patients and their caregivers in longitudinal research. Palliat Med 2006 Dec;20(8):745-754. [doi: 10.1177/0269216306073112] [Medline: 17148529]

\author{
Abbreviations \\ mHealth: mobile health \\ PRISMA-ScR: Preferred Reporting Items for Systematic Reviews and Meta-Analyses extension for Scoping \\ Review
}


Edited by C Dias; submitted 29.08.19; peer-reviewed by E Ding, S Saeed; comments to author 16.09.19; revised version received 08.10.19; accepted 22.10.19; published 06.01.20

Please cite as:

Portz JD, Elsbernd K, Plys E, Ford KL, Zhang X, Gore MO, Moore SL, Zhou S, Bull S

Elements of Social Convoy Theory in Mobile Health for Palliative Care: Scoping Review

JMIR Mhealth Uhealth 2020;8(1):e16060

URL: https://mhealth.jmir.org/2020/1/e16060

doi: $10.2196 / 16060$

PMID: $\underline{31904581}$

CJennifer D Portz, Kira Elsbernd, Evan Plys, Kelsey Lynett Ford, Xuhong Zhang, M Odette Gore, Susan L Moore, Shuo Zhou, Sheana Bull. Originally published in JMIR mHealth and uHealth (http://mhealth.jmir.org), 06.01.2020. This is an open-access article distributed under the terms of the Creative Commons Attribution License (https://creativecommons.org/licenses/by/4.0/), which permits unrestricted use, distribution, and reproduction in any medium, provided the original work, first published in JMIR mHealth and uHealth, is properly cited. The complete bibliographic information, a link to the original publication on http://mhealth.jmir.org/, as well as this copyright and license information must be included. 